\title{
DIFFERING STUDENT VIEWS OF ONLINE LEARNING MODES ACROSS TWO PROGRAMS IN AN AUSTRALIAN UNIVERSITY
}

\author{
Dr Kathryn Dixon \\ Faculty of Education, Language Studies and Social Work \\ Curtin University of Technology \\ k.dixon@curtin.edu.au
}

Dr Kathryn Dixon is the Coordinator of the Training and Development Program in the Faculty of Education, Language Studies and Social Work at Curtin University of Technology in Western Australia. Her major research interests are in Vocational Education, Adult and Continuing Education and online learning. She has completed a $\mathrm{PhD}$ on factors which affect the institutionalisation of educational innovations in organisations and is also interested in the development and impact of national training initiatives and frameworks on the changing structure of higher education. Her current research involves an investigation into the delivery of Enterprise and Vocational Education in Western Australia and ongoing evaluation strategies for professional development for offshore Curtin University of Technology lecturers.

\author{
Dr Lina Pelliccione \\ Faculty of Education, Language Studies and Social Work \\ Curtin University of Technology \\ 1.pelliccione@curtin.edu.au
}

Dr Lina Pelliccione has completed a $\mathrm{PhD}$ in the field of Information and Communication Technology (ICT) related to the adoption and implementation of educational innovations in the learning and teaching process at the tertiary level. She is currently responsible for the coordination of the Bachelor of Education Primary Degree. Lina also coordinates and lectures a range of units which deal with the integration and effective use of ICT in learning and teaching. She has a primary teaching background and her teaching and research interests include: the adoption and implementation of ICT in teaching and learning; enhancing learning through the use of ICT with young children through to adults; electronic portfolios; online learning environments; innovation and change.

\author{
Mr Robert Dixon \\ Faculty of Education, Language Studies and Social Work \\ Curtin University of Technology \\ r.dixon@curtin.edu.au
}

Robert Dixon is a lecturer in the Training and Development Program at Curtin University. He is currently completing his $\mathrm{PhD}$ on the development of professional portfolios for those in educational leadership positions. His other research interests include the development of pedagogical effectiveness indicators for online learning and adult and continuing education. 


\title{
DIFFERING STUDENT VIEWS OF ONLINE LEARNING MODES ACROSS TWO PROGRAMS IN AN AUSTRALIAN UNIVERSITY
}

\begin{abstract}
The sample for this study comprised 108 students who were enrolled in both undergraduate and postgraduate programs in a Western Australian university. The focus areas for investigation included reactions to online delivery, student perceptions of the rates and depth of participation and levels of engagement with the learning process. The results indicated that while the students were technically competent overall, issues associated with equity and access varied between the groups and also between students enrolled in the same units. The sample had also re-conceptualised the notion of 'personal' which moved beyond simple physical proximity to enable the students to create their own community of learners.
\end{abstract}

Keywords: electronic portfolios; reflective practice; online learning

\section{Background}

The university which is the focus of this research delivers a range of programs which include online and flexible approaches to teaching and learning. The sample for this research comprised 108 students who were enrolled in both undergraduate and postgraduate programs in a Department of Education in a Western Australian university. The student sample represented a diverse group as it consisted of young people who were engaged in pre-service teacher training as well as adult learners in the field of training and development. Both internal (face-to-face learners) and external students were part of the sample. As students are the core business of the Department of Education, this research chose to investigate student reaction to and reflections upon these various modes of delivery.

The Training and Development Program has been offered to students completely online since 1995. The program was designed to complement Brennan's (2000) concept of utilising computers as tools to support the teaching and learning process. The initial decision to implement an online approach was influenced firstly, by the financial implications of continuing to offer face-to face teaching. Secondly, the online refinement and development of 
both programs adheres to what Craig (2002); Goddard (1996), and Ruberg, Taylor and Moore (1996) suggest should influence teaching and learning online which includes the need to cater for students who actively avoid face-to-face communication and use online options to a greater extent. The majority of students prefer the current method of delivery, as they are largely adult learners who are engaged in full-time employment and the online nature of the program allows many of them to work at their own pace in between further ongoing commitments.

The students in the sample who were involved in the pre-service teacher training program were enrolled in the Bachelor of Education degree in the Department of Education. This is a four-year degree program which has largely followed a traditional model of delivery and has therefore typically included lectures, tutorials and workshops. Although one of the strategic goals of the university is to increase the engagement with online teaching and learning, the program maintains an ad hoc approach to online delivery which relies ultimately upon the skill level and interest of individual lecturers within the department.

\section{Literature Review}

Government policies, changes in the post compulsory education sector and the availability of technologies are influencing the provision of education and training in Australia. Global and local trends are changing the nature of work and with that, the needs for education and training in the twenty first century. It appears that we may be moving towards an information economy' in which new knowledge-based industries will emerge. The 'knowledge worker' will be required to develop new skills and evolve these skills within a constantly changing work environment (Harper et al, 2000). According to Warner, Christie and Choy (1998), the term 'online' can be defined as the use of cyber systems such as the intranet and internet for the purpose of communicating and teaching and learning. Salmon (2000) sees the term as covering a range of technologies such as informatics, computer-assisted instruction and computer-mediated conferencing. Brennan (2000) defines it as requiring situations where computers support teaching and learning, there is a mixture of computer support and online delivery or computer technology alone delivers education and training. 
Rapid advancements in current technology have meant that flexible delivery has advanced equally rapidly, offering students wide choices in learning methods. According to Choy, McNickle and Clayton (2002) the growth of online technologies has resulted in the development of online social networks and the ability to communicate with others on a regular basis. Students are able to overcome feelings of isolation and disengagement with the learning experience as they create their own communities both within the confines of the online material and beyond. Harper et al. (2000) see online technologies as attracting teachers and trainers to the delivery option because of the 'anytime', 'anywhere' philosophy that underpins much of this approach to learning. They warn however, that teachers working in this environment must be aware of the changing nature of student literacy with regard to online competency as this is seen to impact upon successful engagement with the learning materials and process.

Graham and Scarborough (1999) maintain that online learning environments have provided important contact between students and teachers and have therefore helped to overcome feelings of isolation previously characteristic of traditional distance education and training which consisted of primarily printed text resources and communication via post. Much of the literature supports the notion that students who tend to avoid communication with fellow students and teachers in face-to-face contexts tend to contribute much more in online learning situations (Bellman, Tindimubona \& Arias Jr. 1993; Goddard 1996; Harasim 1993; Ruberg, Taylor \& Moore 1996). Teachers at all levels need to remember however, that teaching has value only if it promotes student learning. This learning needs to include conceptual growth, working collaboratively and communicating. The main focus of teaching and learning according to Craig (2001) must shift from content presentation to a combined, dynamic focus of how students approach learning, multiple styles of delivery and ongoing inquiry. Goodwin (1993) found that learners in higher education settings perceived the Internet as an appropriate delivery medium but warned that frustration with technical aspects could lower student satisfaction and ultimate achievement of learning outcomes. Online learning challenges 
learners to develop new skills and re-conceptualise learner requirements. According to Cornell and Martin (1997) challenges for facilitating online learning include the maintenance of learner motivation, the degree of acceptance by student and teacher, the prior knowledge of each participant, the students' attitudes towards technology, the level of content and the degree of interactivity. Cornell and Martin (1997) also included aspects such as ease or difficulty in using the system and basic communication skills as having an impact on the successful implementation of online learning. Similar issues were raised by CorrentAgostinho and Hedberg (1998) in their implementation of online learning in a post-graduate educational technology course. Their research found that students involved in the program believed that the major problems to be overcome included lack of motivation to participate, procedural confusion and technical difficulties. Many universities have implemented education via computer-mediated communication (Goodwin, 1993; Jiang, 1998; Nnazor, 1998). Students perceived that they had attained comparable academic achievement via online course delivery and believed that teachers who were involved in flexible delivery of materials were more inclined to encourage student participation and teacher-student, student-student interaction than those teaching in more traditional modes. Educational approaches which are based on constructivist principles and findings from cognitive psychology have introduced new conceptualisations of learning and instruction (Brooks and Brooks, 1993; Marshall, 1996). The importance of learner-directed environments is growing and computer technologies are given attention as tools for enabling the objectives of constructivist principles. Constructivism demands that the individual learner is active in the process of constructing knowledge (Dewey, 1916; Piaget, 1952). Importance is assigned to the way learners make sense of what they are learning in the social context (Salamon \& Perkins, 1998; Vygotsky, 1978). Participants bring their own experiences and interpretations to the community and as a result, the community is enriched with a number of perspectives to review in relation to their own. Participants engage in processes of negotiation, augmentation and case building to resolve differences and these processes are crucial to individual development (Brown et al., 1992).

Oliver and Omari (1999) found that students believed the online environment required them to invest greater amounts of time in preparation for class activities and as such, added to their 
workload. Despite this however, the students reported a positive response to the new learning environment. Alexander and McKenzie (1998) in their report on the evaluation and implementation of technology-based learning systems in higher education claimed that while there were many successful online teaching implementations, careful project selection, retraining for teaching in this mode and support for learners using this mode were critical to achieve effective outcomes for online technologies. There is evidence in the literature to suggest that online learning is growing rapidly (Goodyear, Salmon, Spector, Steeples \& Tickner, 2001) and according to Leonard and Guha (2001) online learning offers students and institutions great flexibility. As a result, online courses are increasing in number and scope. However, it remains to be seen whether this is translating into improved learning. Ongoing evidence from the literature suggests that the maturation of online delivery will be realised once innovators begin to develop realistic strategic, pedagogical and commercial models as we move further into the twenty first century.

\section{Research Method}

Patton (1990) and Denzin \& Lincoln (1994) noted that within the interpretive approach there are many methods - however they all share the same philosophical assumption, which is that reality is constructed by individuals interacting with their social worlds (Merriam, 1998). In the present study an interpretative method was adopted using a case study approach, with groups of internal and external students within one Education Department as the case. This method of describing and revealing what happens in the dynamic social environment of a student group appeared more appropriate, rather than a more quantitative approach. The assumption is made that the findings of this study are not only pertinent to these student groups but also to other students studying in an online environment.

\section{The Instrument}

The survey instrument utilised in this study was originally designed to identify the needs of the online learners in two very distinct groups of students. Those students participating in the Bachelor of Education course who were classified as internal students and those enrolled in the Training and Development program classified as external students. The survey titled 
Meeting Individual Online Learning Needs aimed to investigate the students' reactions to online delivery, their rates and depths of participation in this environment, and ultimately their levels of engagement with the learning process. The researchers were particularly interested to investigate the online experiences of these two cohorts and whether there were similar concerns and issues that were specific to online learning. The format consisted of checklists, multiple choice responses, several likert-type scales and open-ended questions. The survey was administered at the end of Semester One, 2003.

\section{Results}

The results indicated that while the students involved in the pre-service Bachelor of Education program had no option other than to study particular units in mixed mode, the Training and Development students were largely attracted to the program because of the fact that all units are offered online and in distance mode. These students (32\%) indicated that their physical distance from the university had firstly influenced their decision to enrol in the course followed closely by the influence of increasingly busy work schedules upon their ability to study on campus. When asked about issues concerned with flexibility and access students (43\%) noted that the mode of delivery enabled them to access materials after hours and at their convenience. Eighteen percent of the sample indicated that the fluid time frame for their engagement with the unit attracted them to this mode of delivery.

It is clear that the majority of both the Bachelor of Education and the Training and Development students were highly competent in utilising the many technical aspects of online delivery. These included using the WebCT environment, sending an email, posting messages on discussion boards, involving themselves in synchronous and asynchronous discussion, downloading files from WebCT and searching the internet. This is interesting given the fact that the average age of the students enrolled in the Bachelor of Education is currently $18-25$ years of age, while the Training and Development students on average fall between $35-45$ years of age. This apparent technical skill level on the part of the Training and Development students could be due to a number of factors. Firstly, as these students are all involved in fulltime employment in the Training and Development field (some in management positions) they 
are involved in regular and ongoing professional development in not only technical skills but a wide range of associated professional areas. Secondly, these students have had exposure to step by step instructions regarding online access and this information is sent to them prior to the beginning of each semester in hardcopy.

One of the items in the questionnaire required the students to indicate the level of their average weekly access of their online learning environment associated with the unit. Interestingly, the students who were enrolled in the Bachelor of Education program and who therefore enjoyed the additional face-to-face components of the program were more likely to access this environment. It may be that students working in face to face mode are more frequently encouraged by both their lecturers involved and their peers to regularly engage in the online process. Table 1 identifies the average weekly online access by students.

\begin{tabular}{|l|c|c|}
\hline & Bachelor of Education (n=74) & Training \& Development $(\mathrm{n}=34)$ \\
\hline Never & $0 \%$ & $0 \%$ \\
\hline Once & $10.8 \%$ & $24.5 \%$ \\
\hline Twice & $24.3 \%$ & $29.4 \%$ \\
\hline $3-5$ & $44.6 \%$ & $29.4 \%$ \\
\hline More than 6 & $20.3 \%$ & $14.7 \%$ \\
\hline
\end{tabular}

Table 1: The Average Weekly Online Access by Students.

It may be that students working in face to face mode are more frequently encouraged by both their lecturers involved and their peers to regularly engage in the online process. The Bachelor of Education students commented that having access to regularly updated information regarding the structure, content and assessment protocols for the unit influenced their high level of use. The level of access on a weekly basis of the Training and Development of students while not as high is understandable given that they are all engaged in full-time employment and study part-time. 
When the sample was asked to comment upon the online environment features and resources that they used on a regular basis the majority of the Bachelor of Education students (74\%) and the Training and Development students $(88 \%)$ indicated that they preferred to participate in the online discussion element within each unit. The Training and Development students were required to engage in the online discussion in a very structured manner due to the assessment components of the unit. In order to complete the unit successfully these students were asked to post their critical analyses of three distinct readings. It became clear in the early stages of the semester that once these students had overcome their reticence in responding publicly they were more inclined to utilise the online discussion component in order to interact in other less structured and more supportive ways. This resulted in the creation of sub-sets of students who were interested in developing ongoing communication and support networks.

Even though the majority of Bachelor of Education students clearly used face-to-face communication processes it is interesting to note that $82 \%$ of the sample also used the email facility to communicate with the unit lecturer. It appears that these students were seeking additional feedback and direction in weekly tutorials. It may be that regardless of the issue at hand the students expected a fairly immediate response to any enquiry and this reflects changing trends in the workplace in general. The Training and Development students may have begun to perceive the lecturer as part of their own cohort as this would explain the high percentage $(97 \%)$ of preference for the use of the discussion board to communicate with the lecturer.

The Bachelor of Education students were asked to comment on changes they would like to make to the WebCT environment. Overwhelmingly the sample (41\%) indicated they preferred to maintain the current level of delivery. In addition, $18 \%$ of the students believed that other units in the program should adopt the WebCT environment. The positive responses seemed to suggest that students believed that this approach aided communication, allowed them ready access to relevant course details and updated course information. This group also acknowledged that the WebCT environment was easy to use and a perceived bonus was that the online resource was able to be accessed from home. Training and Development students 
were asked to comment on components of the unit which were useful. Responses indicated that these students had found the direct link between online delivery and assessment to be beneficial. They also felt that the unit content and method of delivery encouraged deeper thinking and increased personal reflection of the new learning. When asked what they would like to change about the unit the majority (53\%) of the Training and Development students suggested that the unit should remain in its current form and surprisingly $12 \%$ asked for more online contact.

\section{Conclusion}

The results of the study reflect Harper's et al., (2000) view that moving to an online mode requires a reconceptualisation of teaching and learning. The students involved in a mixture of face-to-face and online learning had high expectations of continual and ongoing communication with and feedback from their lecturer. In this way academics embarking on a mixed mode approach need be aware that this increased interaction can extend the working day. The philosophy of "user pays" has become embedded in the university culture and the technology within the structure of various units has facilitated this.

The sample believed that the current approach to WebCT in the University assisted communication and allowed them ease of access to constantly changing course details and updated information. Over time students studying totally in an online mode were more likely to develop their own social networks. This enhanced their learning opportunities as these students were inclined to mentor each other with regard to assessment and general progress through the unit content. The findings of this study reflect those of Graham and Scarborough (1999) in that the online learning environments provided in both the Bachelor of Education and Training and Development programs seem to have provided additional opportunities for student interaction and as such reduce the potential isolation of students in both face-to-face and totally online. One of the key benefits of implementing online approaches in the Bachelor of Education and Training and Development program appears to have been the ease of access to a multitude of resources. These resources varied from gathering information from the World Wide Web, and course materials but more importantly accessing other individuals both 
globally and within the program itself. In this way the enhanced interaction afforded by the online approaches facilitated improved teaching, deep learning and reflective practice.

The challenge for universities and therefore instructional designers is how to increase the level and depth of interactivity within the online space in order to further empower students to truly become independent learners. In this way they can move further towards developing what Harper et al., (2000) describe as "knowledge workers" whereby they develop and evolve critical thinking skills which will equip them for a constantly changing work environment.

\section{References}

Alexander, S., \& McKenzie, J. (1998), An evaluation of information technology projects for university learning, Canberra, Committee for University Teaching and Staff Development.

Bellman, B, Tindimubona, A., \& Arias Jr, A. (1993), "Technology transfer in global networking”, in L. M. Harasim (Ed.), Global networks: Computers and international communication, Massachusetts Institute of Technology, Cambridge Mass., pp. 237-54.

Brennan, R. (2000), All that glitters is not gold: Online delivery of education and training, NCVER, Adelaide, South Australia.

Brooks, J. B., \& Brooks, M.G. (1993), In search for understanding: The case for constructivist classrooms, Association for Supervision and Curriculum Development, Alexandria, VA..

Brown, A.L., Ash, D., Rutherford, M., Nakagawa, K., Gordon, A., \& Campione, J.C. (1993), "Distributed expertise in the classroom", in G. Salamon (Ed.), Distributed cognitions: Psychological and educational considerations (p. 188-228), Cambridge University press, New York.

Choy, S, McNickle, C., \& Clayton. (2002), Learner expectations and experiences: An examination of student views of support in online learning, NCVER, Adelaide, South Australia. 
Cornell, R, \& Martin, B.L. (1997), “The role of motivation in web-based instruction”, in B.H. Khan, (Ed.), Web-based instruction, Educational Technology Publications, Englewood Cliffs, NJ, pp. 93-100.

Corrent-Agostinho, S., \& Hedberg, J. (1998), 'Creating a postgraduate virtual community: Issues for authors and students as authors', Paper presented at the Open Learning Australia Virtual Conference, 16-27 March, 1998.

Craig, D. V. (2002,. 'View from an electronic learning environment: Perception and patterns among students in an online graduate education course'. Journal of Educational Technology Systems, 30 (2), pp. 197-219.

Denzin, N., \& Lincoln, Y. (1994), Handbook of qualitative research, Sage, California:

Dewey, J. (1916), Democracy and Education. Free press, New York.

Goddard, J. M. (1996). "E for engagement, E for email". Paper presented at the Making new connections: ASCILITE '96 Conference, 2-4 December, Adelaide, South Australia.

Goodyear, P., Salmon, G., Spector, J.M., Steeples, C., \& Tickner, S. (2001), “Competencies for online teaching: A special report". Educational Technology Research and Development, $1,65-72$.

Goodwin, B. N. (1993), “A study of the perceptions and attitudes exhibited by distance education students and faculty at the University of Phoenix online program”, Doctoral dissertation, University of Arizona, AZ, 1993. Dissertation Abstracts International, 55, 0939.

Graham, M., \& Scarborough, H. (1999), “Computer mediated communication and collaborative learning in an undergraduate distance education environment", Australian Journal of Educational Technology, 151, pp.20-46.

Harasim, L. M. (1993). "Networlds: Networks as social space" in L. Harasim (Ed.), Global networks: Computers and international communication, , Massachusetts Institute of Technology, Cambridge, Mass., pp. 15-34.

Harper, B, Hedberg, J, Bennett, S., \& Lockyer, L. (2000). “The online experience: The state of Australian online education and training practices", NCVER, Adelaide, South Australia. 
Jiang, M. (1998), "Distance learning in a web-based environment: An analysis of factors influencing students' perceptions of online learning”. Doctoral dissertation, State University of New York, NY, 1998. Dissertation Abstracts International, 59, 4044.

Leonard, J. \& Guha, S. (2001), "Education at the crossroads: Online teaching and students' perspectives on distance learning". Journal on Research on Technology in Education, 34, (1), p.51-57.

Marshall, H. (1996), "Recent and emerging theoretical frameworks for research on classroom learning: Contributions and limitations', Educational Psychologist, 31, p. 147-244.

Merriam, S. (1998), "Qualitative research and case study applications in education”, JosseyBass Publishers, San Francisco.

Nnazor, R. (1998), "Understanding the advent of information technology in teaching at the university. : A case study of the University of British Columbia”, Doctoral Dissertation, University of British Columbia, BC, 1998. Dissertation Abstracts International, 59, 4378.

Oliver ,R., \& Omari, A. (1999), "Using online technologies to support problem-based learning: Learners' responses and perceptions", Australian Journal of Educational Technology, $151(5)$, pp. 8-79.

Patton, M. (1990), "Qualitative evaluation methods $2^{\text {nd }}$ Edition”, Newbury Park, California, Sage.

Piaget, J. (1952), “The origins of intelligence in children”. Norton, New York.

Ruberg, L. F, Taylor, C.D., \& Moore, D. M. (1996), “Student participation and interaction online: A case study of two college classes- freshman writing and a plant science lab", International Journal of Educational Telecommunications, 21, pp. 69-92.

Salmon, G. (2000), E-moderating: The key to teaching and learning online, Kogan Page, London.

Saloman, G. \& Perkins, D. (1998), "Individual and social aspects of learning”. In P.D Pearson and A. Iran-Nejad (Eds.), Review of Research in Education, 23, p. 1-24.

Vygotsky, L. (1978), Mind in society. Cambridge, MA: Harvard University Press. 
Warner, D, Christie, G, \& Choy. (1998), "The readiness of the VET sector for flexible delivery including online learning", EdNAVet Working Group \& ANTA, Brisbane, Queensland. 